
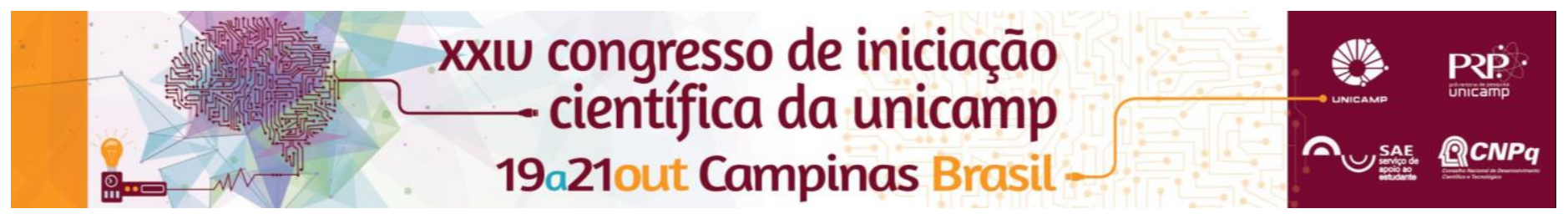

\title{
Avaliação de parâmetros de qualidade de vida e enfrentamento de pacientes oncológicos sob cuidados paliativos na enfermaria do Hospital de Clínicas da Universidade Estadual de Campinas (UNICAMP): um estudo prospectivo, observacional.
}

\author{
Líllian G. B. Fernandes*, Bruna S. Tanios, Karla C. Gaspar, Lígia T. Macedo, Carmen S. P. Lima.
}

\section{Resumo}

A identificação dos sintomas e seus impactos na qualidade de vida de pacientes onclógicos é fundamental para o planejamento de incrementos a cuidados paliativos. Objetivos: Identificar os principais sintomas e indicadores de qualidade de vida e de enfrentamento de pacientes oncológicos em cuidados paliativos internados no Hospital de Clinicas da UNICAMP e avaliar a qualidade do serviço em cuidados paliativos. Métodos: A avaliação foi realizada por meio dos questionários ESAS, POS, FAMCARE-P13 e EMEP. Os dados obtidos foram analisados em forma de proporção. Resultados: 42 pacientes foram incluídos no estudo (idade média: 60 anos, desvio padrão: 11 anos; 23 homens, 19 mulheres). $62 \%$ dos pacientes responderam não estar com dor no momento da aplicação do questionário, entretanto $64,3 \%$ sentiram algum grau de dor nos últimos três dias. Cerca de dois terços dos pacientes referiram outros sintomas, como sonolência, ansiedade, redução do apetite e mal estar. 47,6\% dos pacientes responderam que tentam esquecer a doença e $54,8 \%$ desejam mudar o que lhes aconteceu. 76,2\% dos pacientes disseram estar satisfeitos em relação à disponibilidade dos enfermeiros para responder às suas perguntas e 69\% para com os médicos.

Palavras-chave: cuidados paliativos, qualidade de vida, pacientes oncológicos

\section{Introdução}

A caracterização dos sintomas que alteram a qualidade de vida dos pacientes oncológicos é fundamental para a adequação de cuidados paliativos por eles requeridos. São escassas as informações referentes ao perfil de pacientes oncológicos sob cuidados paliativos e de serviços de cuidados paliativos, particularmente no Brasil. Objetivos: identificar os principais sintomas, indicadores de qualidade de vida e de enfrentamento dos pacientes oncológicos em estágio avançado de doença, internados no Hospital de Clinicas da Unicamp, bem como a avaliação do serviço multidisciplinar que a eles presta assistência.

\section{Resultados e Discussão}

Uma ficha de dados clínicos foi preenchida para cada participante. Os questionários utilizados foram: Edmonton Symptom Assessment Scale (ESAS) (Richardson, 2009), Escala de Resultados de Cuidados Paliativos (POS) (Hearn, 1999), FAMCARE-P139 (Lo, 2009) e a Escala de Modos de Enfrentamento de Problemas (EMEP)(Seidl, 2001). 42 pacientes foram entrevistados (idade média: 60 anos, desvio padrão: 10 anos; 23 homens, 19 mulheres). $83,4 \%$ dos pacientes eram procedentes do sul ou sudeste. $47,6 \%$ tinham como acompanhante o cônjuge e 33,3\%, irmã(o). 66,6\% apresentavam metástases à distância no momento da internação (50\% em peritônio, 39,3\% em fígado, 32,1\%, em pulmões, 19,9\%, em ossos). As principais causas para a internação foram: realização de quimioterapia (28,6\%), sepse ou complicações infecciosas $(16,7 \%)$ e suboclusão intestinal (7,1\%). 62\% dos pacientes não apresentavam dor no momento da aplicação do questionário, 64,3\% sentiram algum grau de dor nos três dias anteriores. $56 \%$ dos pacientes relataram sonolência, $66 \%$ ansiedade, $57 \%$ redução do apetite e $64 \%$ relataram mal estar. $16,7 \%$ dos pacientes responderam que se culpam por sua doença, $47,6 \%$ tentam esquecer este problema e $54,8 \%$ desejam mudar o que Ihes aconteceu. $76,2 \%$ dos pacientes disseram estar satisfeitos com a disponibilidade dos enfermeiros em responder às suas perguntas e $69 \%$ para a disponibilidade dos médicos.

\section{Conclusões}

O câncer trouxe consequências físicas e emocionais, não manejadas de forma satisfatória em nossos casos. Cerca de $30 \%$ dos pacientes estavam insatisfeitos com a disponibilidade de médicos e enfermeiros para responder as suas perguntas. Melhor suporte para sintomas e maior disponibilidade para responder perguntas são necessários nos cuidados paliativos a nossos pacientes.

\section{Agradecimentos}

\section{$\mathrm{PIBIC} / \mathrm{CNPq}$}

Seidl EMF, Troccoli BT, Zannon CMLC. Análise Fatorial de Uma Medida de Estratégias de Enfrentamento. Psic.: Teor. e Pesq. [online]. 2001, vol.17, n.3, pp. 225-234.

Lo C, Burman D, Hales S, Swami N, Rodin G, Zimmermann C. The FAMCARE-Patient scale: Measuring satisfaction with care of outpatients with advanced cancer. Eur J Cancer. 2009; 45(18):3182-8

Hearn J, Higginson IJ. Development and validation of a core outcome measure for palliative care: the palliative care outcome scale. Palliative Care Core Audit Project Advisory Group. Qual Health Care. 1999 Dec;8(4):219-27.

Richardson LA, Jones GW. A review of the reliability and validity of the Edmonton Symptom Assessment System. CurrOncol. 2009 January; 16(1): 55. 